\title{
Reestruturação imobiliária: uma análise dos processos de concentraçáo e centralização do capital no setor imobiliário
}

Sandra Lencioni. Universidade de São Paulo, São Paulo, Brasil.

RESUmo | A análise da produção imobiliária nos traz desafios. O primeiro deles diz respeito aos dados dos quais dispomos para a análise. A segunda dificuldade advém da profunda reestruturação que o setor imobiliário vem passando. Nessa reestruturação, dois processos se destacam: o de concentração e o de centralizaçáo do capital. $\mathrm{O}$ processo de concentração se dá por meio da expansão dos negócios, da ampliação dos mercados, da intensificação da produção e da ampliaçáo do número de equipamentos e trabalhadores. O processo de centralização do capital se dá por meio da associação entre empresas, da absorção de uma pela outra, ou por meio de fusóes de empresas. Outra estratégia que vem transformando o setor é a abertura de capitais na bolsa de valores que amplia as possibilidades de uma empresa de captar recursos no sistema financeiro. Todos esses processos e estratégias são elementos da reestruturação imobiliária.

PALAVRAS-CHAVE | Reestruturação econômica, reestruturação imobiliária, mercado imobiliário, geografia urbana, São Paulo.

ABSTRACT | The analysis of real estate production brings us challenges. The first concerns the data available for analysis: numbers are not always sufficient, usually lack periodicity and often have poor reliability. The second difficulty comes from the deep restructuring that the real estate sector is undergoing. In this restructuring two processes stand out: the concentration and the centralization of capital. The process of concentration of capital comes from the business expansion, the enlargement of markets, the intensification of production, the expansion of the number of urban equipment and workers. The process of centralization of capital comes from the association of companies, the absorption of one by another, or through mergers of companies. Another strategy that is transforming the sector is the opening of capital on the stock exchange, which broadens the possibilities for a company to raise funds in the financial system. All of these process and strategies are elements of the real estate restructuring.

KEY WORDS: economic restructuring, real estate restructuring, real estate market, urban geography, São Paulo.

Recibido el 15 de marzo de 2012, aprobado el 14 de mayo de 2013

E-Mail: slencion@usp.br 


\section{Introduçáo}

Um fato que guarda muito pouco espaço para polêmica é o de que o capitalismo não é mais o mesmo, uma vez que este se reestruturou para garantir sua reproduçáo. Ele teve que se reinventar, se reestruturar, se reconstruir. A palavra 'reestruturação' utilizada para indicar essa mudança, expressa muito bem o que houve, pois é derivada da palavra structura-ae, originada do verbo struere, que tem o sentido original de construir.

Essa nova reconstrução, estrutura que se impóe sobre a anterior, não significa fazer tábua rasa da antecedente. Por assim dizer, a nova estrutura não implica na implosão da anterior. Significa que essa deixou de ser a determinante maior dos processos. Um exemplo bastante ilustrativo sobre a permanência e mudança da estrutura é dado por Léfebvre (1971, pp. 182, 183), quando ele discute a relaçáo entre estrutura, forma e função. Diz ele que entre os séculos XVI e XIX o capitalismo comercial era quem dirigia o processo geral de reprodução social, porém, essa estrutura foi superada por uma nova, a industrial. Isso não quer dizer que o capitalismo concorrencial tenha deixado de existir. Significa, sim, que ele deixou de ser o fundamento maior, o determinante mestre na estruturação da sociedade industrial em desenvolvimento. Continuou desempenhando uma função.

Com esse sentido, de emergência de uma nova estrutura que se impóe sobre a anterior, é que falamos em reestruturação imobiliária, uma vez que uma nova estrutura se impóe sobre a anterior e modifica profundamente o setor imobiliário.

Essa reestruturaçáo imobiliária implica na reestruturaçáo do próprio capital investido no setor, na reestruturação de tudo que envolve a construção - a exemplo das profundas transformaçóes no canteiro de obras e na profissão do arquiteto, e na reestruturaçáo da propriedade da terra, por meio do surgimento de novas formas de propriedade, tais como o leasing imobiliário e o time-sharing.

Trataremos, nesse texto, apenas sobre um aspecto da reestruturação imobiliária. Mais especificamente, de dois processos que consideramos chaves para a compreensão dessa reestruturação. São eles: o processo de concentração e o de centralização do capital no setor imobiliário. Um paralelo com o desenvolvimento urbano é estabelecido por meio da referência à densificação das construçóes nas áreas mais centrais da metrópole e à dispersão do espaço construído que produz uma metrópole contemporânea difusa. Nesse sentido, compreender a reestruturação imobiliária e sua relaçáo com a metamorfose urbana se constitui num grande desafio, considerando a velocidade das transformaçóes que vem ocorrendo, a qual traz muitas incertezas e, na maioria das vezes, essas se assemelham a uma meada de difícil desenredo. As dificuldades sáo de diversas ordens, desde a questáo dos dados sobre o setor imobiliário, em especial sobre o preço dos imóveis, até os problemas de cunho teórico e metodológico.

Iniciamos o texto discutindo o fato de que, embora o produto imobiliário se constitua como uma mercadoria, ele é uma mercadoria particular. Isto porque nenhum imóvel construído é totalmente produzido, dado que a terra, que é condição basilar da produçáo, náo advém de nenhum processo produtivo. Essa particularidade da mercadoria imobiliária é que faz com que a lógica de seu preço 
não seja a mesma lógica das outras mercadorias. E esse aspecto específico tem que ser levado em conta para que se possa compreender a particularidade da dinâmica dos preços nos negócios imobiliários.

\section{O caráter particular da mercadoria imóvel}

Antes mesmo de discutir o caráter particular da mercadoria imóvel vale lembrar a dificuldade inicial que se tem quando investigamos o setor imobiliário. Não são muitos os dados dos quais dispomos e, além do mais, eles não têm uma periodicidade regular e são procedentes de diversas fontes, nem sempre compatíveis umas com as outras. A rigor, o problema reside no fato de que não há uma sistemática de informaçóes sobre o setor imobiliário, como a que existe para outras atividades econômicas, inclusive com padróes internacionais de referencia. Em geral, as analises são feitas com a informação que está disponível, seja com o registro dos imóveis nos cartórios, seja com os dados dos agentes financiadores, seja com os anúncios de imóveis em jornais e até com as informaçóes que se fazem presentes na internet. Todas essas fontes de dados são muito úteis, pois nos aproximam do que acontece na realidade, mas há que fazer ressalvas a todas elas.

Em especial, nos países onde ainda as informaçóes econômicas são imprecisas, a questão não reside apenas na coleta e difusão da informação, mas na qualidade do dado a ser sistematizado. Em geral, as fontes dos dados tem origem em registro de transaçôes de compra e venda em cartórios de imóveis, de órgãos de financiamento de imóveis e de anúncios classificados de jornais e sites na internet. Em todas essas fontes há diversos motivos para que a informação registrada não seja a dos preços realmente praticados e isso torna a qualidade dos dados um problema. É muito comum que os preços anunciados sejam um primeiro preço, em geral mais elevado do que o preço final com que é comercializado o imóvel na hora da conclusão do negócio.

A confiabilidade dos dados é um problema permanente, mas mais importante que a qualidade dos dados é a questão relativa à formação dos preços imobiliários, que se relaciona ao fato do imóvel ser, como dissemos inicialmente, uma mercadoria singular. Nenhum imóvel, nenhum produto imobiliário vendido no mercado, mesmo se construído, é totalmente produzido. Isso vale para uma simples casa até uma torre moderna que desperta nosso olhar. O imóvel construído contém um terreno e o próprio terreno é uma mercadoria. O terreno é uma condição básica da produção imobiliária e previamente necessária para se realizar a construção. Esse fato, o do imóvel sempre conter uma parcela de terra, é que confere a toda mercadoria imobiliária um caráter particular frente às demais mercadorias, que são inteiramente produzidas.

Esse caráter particular da produção da mercadoria imóvel e, por conseguinte, da reproduçáo do capital no setor imobiliário, significa que a lógica do preço de um imóvel não segue a mesma lógica de preço das outras mercadorias, cujos preços tendem a ser derivados das condiçóes em que elas são produzidas. Como é sabido, as mercadorias que são inteiramente produtos do processo de produção industrial têm um preço estimado e autorregulado pelo mercado (Polanyi, 1980). Esse preço guarda relação com o preço médio de produçáo dessas mercadorias, podendo o seu 
preço de mercado se situar um pouco acima ou abaixo dele. Ou seja, o parâmetro para definir o preço de mercado tende a ser uma média do preço de produção.

No caso da mercadoria imobiliária construída, a particularidade é a seguinte: o seu preço de mercado, além de expressar o preço de produção da construção, deve responder também pelo custo do terreno utilizado. Assim, o preço de mercado não corresponde a uma média do preço de produção da construção, porque o preço de mercado contém um faux frais dentro dele; ou seja, além do preço de produção está contido, também, um falso custo de produção. Esse falso custo de produção (que se frise, não faz parte do preço de produção) precisa ser reposto pelo preço de venda do imóvel (o preço da construção, mais o custo do terreno).

O imóvel construído tem, portanto, no preço de venda um componente sem referência na produçáo, que é o terreno, precisamente, a propriedade da terra. Devido ao fato dessa propriedade impor um falso custo de produção ao setor imobiliário, em decorrência da necessidade de se pagar o monopólio pela propriedade do terreno para realizar a produção e negócios imobiliários, outros elementos entram em jogo na determinação do preço do imóvel. Um deles diz respeito à condição da propriedade da terra se colocar como salvaguarda de valor, quer nos momentos de descenso econômico, como uma espécie de refugio, quer nos momentos de expansáo econômica quando se constitui numa possibilidade de desdobramento dos investimentos. Estes são parâmetros que não tem a ver com a produçáo, com a construção do imóvel em si mesmo, mas que acabam interferindo no preço final de venda do imóvel tornando o preço do imóvel construído, independente do seu preço médio de produção.

Essa particularidade da mercadoria imóvel cria uma ilusão, a de que essa relativa independência do preço do imóvel deriva do desenvolvimento urbano e de sua influencia na formaçáo dos preços imobiliários. Ela deriva, na essência, da propriedade da terra e não do fato aparente de que a terra é cara ou porque ela é escassa.

Todas essas condiçóes, ilusóes e possibilidades relativas à propriedade da terra passam a balizar o preço do imóvel no mercado. No caso de um imóvel construído, uma parte do seu preço é determinada pela condição de conter a propriedade da terra e, a outra parte, é determinada pelo preço de produção. Essa condição é pressuposto para que a produção imobiliária se realize e juntas, integradas e mescladas (a condição e a produção), essa dupla determinaçáo constitui o circuito de valorização do capital no setor imobiliário. Esse pressuposto de um custo prévio e anterior à construção que precisa ser reposto no preço final do produto é que faz com que o preço dessa mercadoria - o imóvel construído - se particularize entre as demais mercadorias. É essa particularidade do negócio imobiliário que vai fazer com que seja estratégico para as incorporadoras e construtoras a constituiçáo de um banco de terrenos. Mas esse banco de terrenos tem que ter uma dimensão que não comprometa a disponibilidade de investimento futuros de uma empresa. Isso porque a compra de terrenos significa capital imobilizado.

É essa conclusão que é necessária reter, para que se compreenda a discussão final que aborda a abertura de capitais na bolsa de valores por algumas empresas incorporadoras como uma estratégia de captar recursos. De um lado, para fortalecer o próprio banco de terrenos delas e, de outro, para garantir a continuidade de novos 
investimentos. Essa estratégia dupla se expressa na necessidade de se aumentar a magnitude de capital para se situar com vantagens no mercado. Daí que cada vez mais se impóem as grandes empresas, que concentram e centralizam capitais.

\section{Reestruturação imobiliária. O processo de concentraçáo e de centralizaçáo do capital}

Como dissemos no início, o capitalismo já não é mais o mesmo. Teve que reinventar a si próprio e a reprodução do capital em geral continua a despeito das crises com periodicidade cada vez menor e dos fantasmas das bolhas imobiliárias que percorrem o mundo.

A reprodução do capital em geral diz respeito ao capital como um todo e serve para compreendermos o movimento geral de sua reproduçáo. Trata-se, na verdade, de uma forma abstrata. Na realidade, o que temos são capitais fracionados - fraçóes de um todo; fraçóes do capital em geral, que funcionam como se fossem independentes. Nas palavras de Aglietta (1979) o "capital se encontra, por natureza, fracionado em capitais que constituem centros de decisóes individuais, autônomos, do ponto de vista de sua valorização" (p. 189). Essas fraçóes do capital estabelecem concorrência entre si. E é por meio dessa concorrência que se desenvolvem as empresas e se constituem as grandes empresas e os grupos econômicos.

Esse termo 'grande empresa' assume, aqui, um sentido genérico. Busca apenas se referir ao tamanho da empresa, exprimindo a magnitude de seu capital e a importância que ela tem no mercado. Não tem, portanto, um sentido conceitual. O que importa é reter que por meio da concorrência capitalista se constituem grandes empresas. O fato das grandes empresas estarem agrupadas em um grupo econômico ou não, não importa para os objetivos desse texto. ${ }^{1}$ Portanto, estamos usando o termo 'grande empresa' com o sentido comum. Com esse sentido é que iremos mostrar que são as grandes empresas do setor imobiliário que se tornam ainda maiores.

De maneira geral, o crescimento de uma empresa pode se dar por meio do processo de concentração de capitais ou pelo processo de centralização de capitais. Ambos os movimentos são expressôes da concorrência capitalista. Em geral, há uma grande-confusão ao se falar em processo de concentração e em processo de centralização do capital. Eles se constituem em processos de natureza bastante distintas e náo devem ser confundidos. Vale dizer, ainda, que esses processos podem ocorrer ao mesmo tempo, sendo a separação apenas analítica, mas útil para compreendermos o que está ocorrendo na dinâmica do capital.

\section{O processo de concentração do capital}

Por meio da expansão dos negócios, da ampliação do mercado, da intensificando da produção, da ampliação do número de equipamentos e de trabalhadores, dentre outras estratégias, as empresas se tornam cada vez maiores, concentrando capitais. Esse processo leva a uma maior acumulação de capitais; baseia-se, portanto, na

1 Entende-se por grupo econômico um conjunto de empresas de natureza e especificaçóes diversas, que estabelecem relaçóes funcionais e financeiras entre si e que são orientadas por uma política comum, salvaguardando, contudo, a autonomia jurídica de cada uma delas. 
acumulação. Por exemplo, a expansão do número de gruas de uma construtora significa maior concentração de meios de produção sob a forma de capital fixo. Essa expansão do número de gruas concentra, portanto, capitais, precisamente capital fixo. Isso se desdobra numa maior capacidade técnica da empresa e por corolário há maior possibilidade de se acelerar o processo construtivo e de se obter vantagens concorrenciais.

Outros exemplos ainda podem ser dados. O aumento do número de funcionários de uma incorporadora também significa concentração de capital; nesse caso, concentração de capital variável. $\mathrm{O}$ crédito obtido num banco aumenta o capital-dinheiro de uma empresa e, consequente, sua capacidade de investimento, expressando, também um processo de concentração de capital. O financiamento conseguido junto a um banco privado ou a um banco publico de desenvolvimento também é uma forma de concentrar capital, tanto quanto inúmeros outros expedientes, como compra de títulos, papéis, notas promissórias, etc.

Mas queremos chamar atenção para um caso específico de concentraçáo do capital das empresas que se processa por meio da abertura de seus capitais na bolsa de valores. Por meio desse expediente as empresas se agigantam. Elas podem capturar dinheiro (capital-dinheiro) para financiar sua expansão e seus planos de investimentos. A abertura de capitais na bolsa de valores se constitui, portanto, num processo de concentração de capitais e vem se tornando um expediente bastante utilizado pelas incorporadoras. Por isso, é que damos destaque à discussão sobre a abertura de capitais na bolsa de valores porque essa estratégia trouxe grandes mudanças ao setor imobiliário. Esse expediente se constitui numa característica da reestruturação imobiliária nos dias atuais.

O processo de concentração de capital é importante reter. Diz respeito a um fato quantitativo e está relacionado a um processo que altera o tamanho, a magnitude, do capital de uma empresa. Com essa magnitude de capital aumentada a empresa busca garantir maiores condiçóes de se impor no mercado e enfrentar com vantagens a concorrência intercapitalista e eventuais obstáculos à reprodução do seu capital.

\section{O processo de centralização do capital}

O processo de centralização diz respeito a um fato qualitativo. Ele é a expressão máxima da concorrência inter-capitalistas. Por meio do processo de centralização de capitais há uma reorganização dos ciclos de valorização dos capitais que se apresentam fracionados.

O processo de centralização do capital se constitui num processo de concorrência entre 'fraçóes do capital'. Essa concorrência reorganiza essas frações de capital, ou seja, ela reorganiza os capitais fracionados, os capitais autônomos. Em síntese, o que isso significa? Significa um processo no qual há a expropriação de um capitalista pelo outro.

Identificamos três formas clássicas de centralização do capital, que podem ser visualizadas na Figura 1: por meio da absorção de uma empresa pela outra; por meio da associação entre empresas e por meio da fusão delas. Suponhamos que temos 3 empresas atuando no mercado: a empresa A, a empresa B e a empresa C. No caso em que a empresa A compra a empresa B, passamos a ter apenas duas empresas: a 
empresa A e a empresa C. Se a empresa A e a B se associam, passamos a ter a empresa $\mathrm{AB}$ e a empresa $\mathrm{C}$. Nesse caso, das 3 empresas que atuavam no mercado passamos a ter 2 , sendo que a única que continua sendo a mesma é a empresa $C$, já que não há mais a empresa $A$ e nem a empresa $B$; mas sim, a empresa $A B$. E, no caso em que as 3 empresas se fundem temos a empresa $\mathrm{D}$, uma vez que a fusão fez desaparecer cada uma delas, a empresa A, a empresa B e a empresa C. Mas, surgiu outra, a empresa D, que expressa a fusão das 3. Nesse caso temos, agora, apenas 1 empresa no mercado.

FIGURA 1 | Formas clássicas de centralização do capital


FUENTE ELABORAÇÃO SANDRA LENCIONI E ANA PAULA CAMILO PEREIRA

No caso da absorção e da associação, das 3 empresas que atuavam no mercado, este, agora, apresenta apenas duas e, no caso da fusão, há apenas uma. Não houve nenhuma mudança quantitativa no interior de cada uma delas, em termos de número de empregados, etc. $\mathrm{O}$ que houve foi uma mudança qualitativa, uma mudança jurídica na propriedade do capital de cada uma delas. Isso quer dizer que houve uma reorganizaçáo na propriedade dos capitais. Houve, repetindo, uma redução do numero de empresas atuando no mercado e, consequentemente, se passou para outro patamar de concorrência. ${ }^{2}$

Em síntese, como dissemos, a centralização de capitais se constitui num processo que significa a expropriaçáo de um capitalista pelo outro. Trata-se, sem dúvida, de uma forma agressiva de conquista de mercados e se constitui o elemento central da reestruturação capitalista das décadas finais do século xx. Tomando-se a maior economia do mundo, em 1983, os Estados Unidos realizaram 2.087 fusóes. Em 1990, esse número passou para 4.239 e, em 1999 para 9.599, indicando a importância que as fusóes e aquisiçóes foram tendo nessa década, quando a restruturaçáo capitalista já estava francamente em curso. ${ }^{3}$

2 Na mídia se fala muito em fusão, mas muitas vezes o que se tem é aquisição.

3 Os dados referem-se apenas às transaçóes envolvendo 5 milhôes de dólares ou mais. Fonte dos dados: U. S. Census 2000. 
Referidos como fusóes e aquisiçóes de forma geral, a Figura 2 registra o seu crescimento no mundo, revelando a importância das fusóes e aquisiçóes na década de 90 e indicando que o ano de 2007 foi o de maior número de transaçôes.

GRÁfico 1 | Fusões e aquisiçôes anunciadas no mundo, 1985-2011

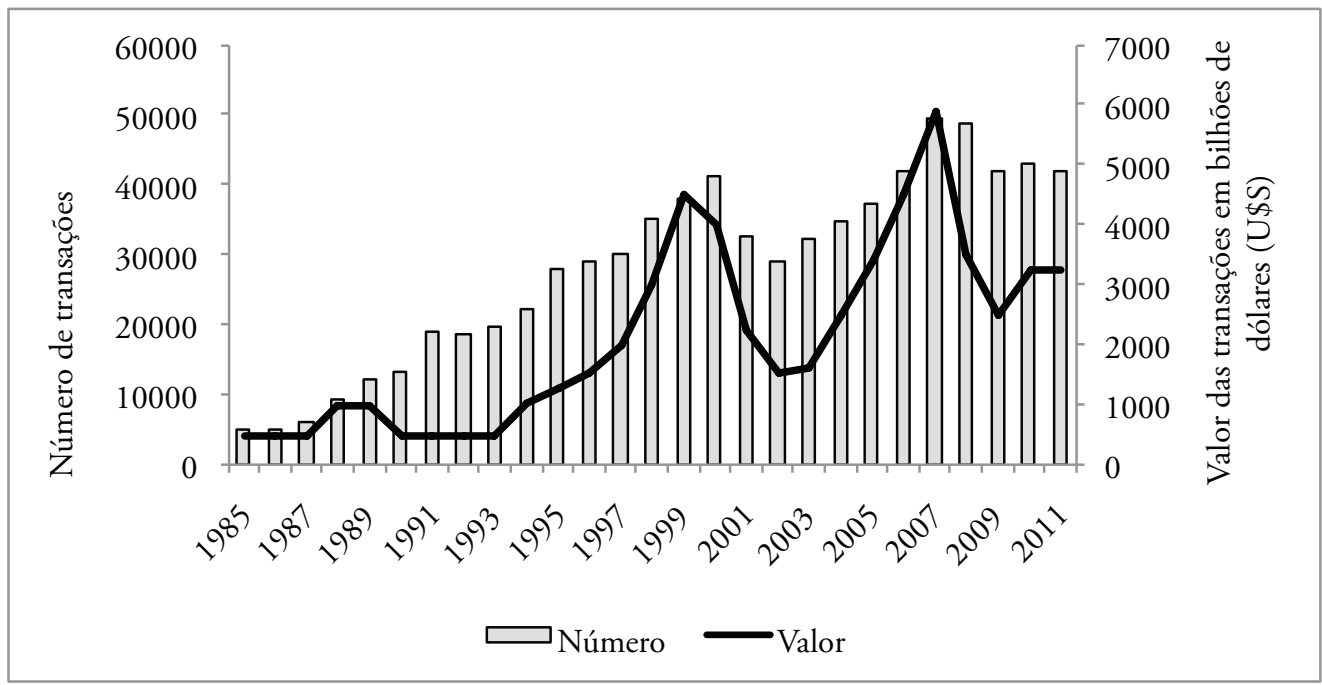

FONTE INSTITUTE OF MERGERS, ACQUISITIONS AND ALLIANCES. DISPONÍVEL EM HTTP://WWW.IMAAINSTITUTE.ORG/STATISTICS-MERGERS-ACQUISITIONS.HTML

$\mathrm{Na}$ América do Sul, o maior número de fusóes e aquisiçôes anunciadas foi em 2011. Embora a série temporal seja mais restrita, o peso da década de 90 é nitidamente visível, conforme a Figura 3. O Brasil possui o maior número de fusóes e aquisiçóes anunciadas entre os anos de 2007 e 2008 conforme pode ser visto na Figura 4.

GRÁfico 2 | Fusões e aquisiçôes anunciadas na América do Sul, 1995-2011

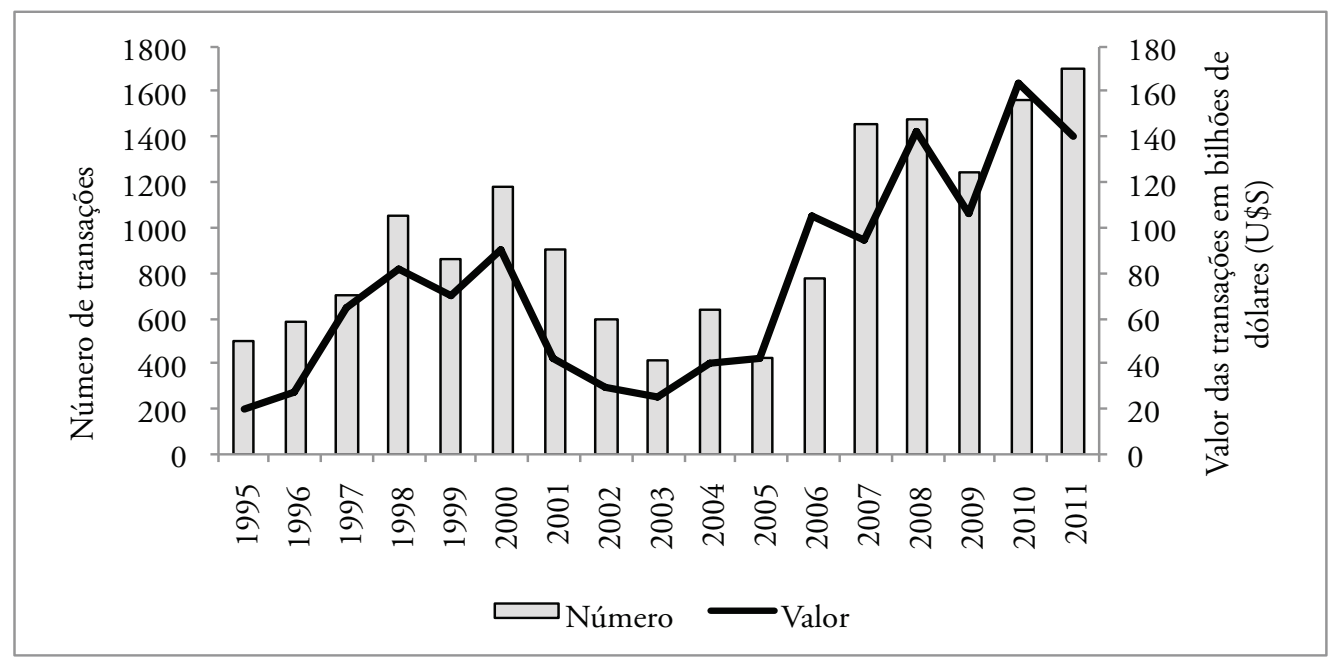

FONTE INSTITUTE OF MERGERS, ACQUISITIONS AND ALLIANCES. DisPONÍVEL EM HTTP://WWW.IMAAINSTITUTE.ORG/STATISTICS-MERGERS-ACQUISITIONS.HTML 
GRÁFICo 3 | Fusóes e aquisiçóes anunciadas no Brasil, 1993-2011



FONTE INSTITUTE OF MERGERS, ACQUISITIONS AND ALLIANCES. DISPONÍVEL EM HTTP://WWW.IMAAINSTITUTE.ORG/STATISTICS-MERGERS-ACQUISITIONS.HTML

O crescimento do número de aquisiçóes e fusôes é bastante expressivo a partir de 2006. Embora esse gráfico não distinga se as fusóes e aquisiçóes anunciadas envolvem capitais forâneos ou não, pelo movimento da economia, é certo que o predomínio é de fusóes e aquisiçóes que envolveram capitais transnacionais.

O trabalho de Miranda; Martins (2000) sobre fusóes e aquisiçóes de empresas no Brasil, enfocando a década de noventa, aponta que nessa década se inicia uma diferença importante em relação às décadas anteriores: a forma de conquista de mercados já não tem mais como forma usual a instalação de filiais ou a construção de novas plantas. Isso porque as fusóes e as aquisiçóes transfronteiriças passam a se constituir no principal instrumento de penetração nos mercados (Miranda \& Martins, 2000, p. 67) (grifo nosso). Apontam como motivadores das mudanças na forma de conquista de mercados, a desregulamentação das economias nacionais, a alteração nos padróes tecnológicos de algumas indústrias e de alguns setores de serviços, alguns imperativos colocados pela globalização e pelas finanças e, ainda, o elevado nível de liquidez dos bancos e empresas transnacionais.

As notícias sobre fusóes e aquisiçóes surgem frequentemente nos jornais do Brasil. Entre 1994 e 2011, em 16 anos, o número de fusóes e aquisiçôes quintuplicou. Em 1994 o número de fusóes e aquisições foi de 175, segundo os dados da KPMG (2011) e o ano de 2011 indica um grande número de operaçóes de fusóes e aquisições realizadas, da ordem de 817 , envolvendo transaçóes quer apenas relativas às empresas de capital brasileiro, quer compreendendo negócios com empresas estrangeiras.

Em 2011, segundo o Quadro 1, as fusôes e aquisiçôes envolvendo apenas capital brasileiro e as abrangendo negócios com estrangeiros tem praticamente igual posição, correspondendo, cada uma, a praticamente $50 \%$ das negociaçóes efetuadas. Das transaçóes envolvendo negócios com estrangeiros, destacam-se expressivamente as empresas estrangeiras que adquiriram de brasileiros capital de empresa estabelecida no Brasil. Isso reafirma o que destacamos anteriormente, que as fusóes e as aquisiçóes transfronteiriças passam a se constituir no principal instrumento de penetraçâo 
nos mercados. Isso permite afirmarmos que vem ocorrendo uma desnacionalização das empresas brasileiras e que os territórios nacionais passam, de fato, a serem mais territórios globais que nacionais.

QUADRo 1 | Fusóes e aquisiçóes efetuadas no Brasil, 2011

\begin{tabular}{|l|c|}
\hline \multicolumn{1}{|c|}{ TRANSAÇÕES } & 20I2 \\
\hline Transaçóes envolvendo apenas empresas de capital brasileiro & 342 \\
\hline Transaçóes envolvendo negócios com estrangeiros & 474 \\
\hline $\begin{array}{l}\text { Empresa de capital majoritário adquirindo de brasileiros capital de empresa estabelecida } \\
\text { no Brasil }\end{array}$ & 296 \\
\hline $\begin{array}{l}\text { Empresa de capital majoritário brasileiro adquirindo de estrangeiros capital de empresa } \\
\text { estabelecida no exterior }\end{array}$ & 37 \\
\hline $\begin{array}{l}\text { Empresa de capital brasileiro, adquirindo de estrangeiro empresa de capital estrangeiro } \\
\text { estabelecida no Brasil }\end{array}$ & 30 \\
\hline $\begin{array}{l}\text { Empresa de capital majoritário estrangeiro adquirindo de estrangeiros capital de empresa } \\
\text { estabelecida no Brasil }\end{array}$ & 102 \\
\hline $\begin{array}{l}\text { Empresa de capital majoritário estrangeiro adquirindo de brasileiros capital de empresa } \\
\text { estabelecida no exterior }\end{array}$ & 9 \\
\hline Total de transaçóes & $\mathbf{8 1 6}$ \\
\hline
\end{tabular}

FONTE ELABORAÇÃo PRÓPRIA. PESQUiSA DE FUSÓES E AQUisiçóES 20 I I, 40 TRIMESTRE. ESPELHO DAS TRANSAÇÓES REALIZADAS NO BRASIL. KPMG. HTTP://WWW.KPMG.COM/BR/PT/ ESTUDOS_ANALISES/ARTIGOSEPUBLICACOES/DOCUMENTS/CF_FUSOES_AQUISICOES/2OII/ FA_2OTRIM_II_SET.PDF

\section{Fusôes e absorçôes no setor Imobiliário do Brasil}

Até agora falamos do setor imobiliário como um todo. No entanto, para abordarmos as fusóes e aquisiçóes desse setor da economia os dados dos quais dispomos e que estão sob a rubrica 'setor imobiliário' não abrangem a atividade de construção, mas apenas os produtos e empreendimentos imobiliários. Assim, a análise que fazemos se restringe a esses produtos e empreendimentos. A análise recai, portanto, sobre o Imobiliário restrito aos produtos e empreendimentos imobiliários. Corresponde ao termo Real State, em inglês.

Em 2011 foram realizadas 11 transaçóes de fusóes e absorçốes de empresas que atuam no Imobiliário, ocupando a $5^{\text {a }}$ posição no ranking de transaçóes no Brasil. Dessas, predominam as negociaçóes domésticas, envolvendo apenas empresas de capital brasileiro. O grande número de fusóes e aquisiçóes foi nos anos precedentes: 41 em 2010, em $3^{0}$ lugar no ranking setorial de transaçôes, 23 em 2009, em $4^{0}$ lugar no ranking setorial de transaçóes, 41 em 2008 e 51 em 2008, em $3^{0}$ lugar no ranking setorial de transaçóes. A posição no ranking de transaçôes, a despeito do número delas, indica a importância que tem essa estratégia de competição (fusóes e absorçôes) no setor. Em suma, o Imobiliário (Real State) se constitui num espaço de forte centralização do capital no Brasil.

Poderíamos tratar das associaçóes de capitais, outra forma de centralização do capital. No entanto, não há dados disponíveis. Mas convém chamar atenção para o fato de que no Imobiliário (Real State) a associação de empresas é muito comum, 
em especial para a realização de um ou vários empreendimentos específicos. Muitas empresas se associam para a realização de um ou vários empreendimentos imobiliários estabelecendo uma sociedade exclusiva. É usual as empresas estabelecerem, por meio de um contrato, uma sociedade específica voltada para uma determinada atividade, formando uma SPE — Sociedade de Propósito Específico.

Além das fusóes, absorçóes e associaçóes de empresas, é muito comum no setor imobiliário outra forma de centralização do capital. Essa forma diz respeito à subcontratação, muitas vezes referida como terceirização, na qual se estabelece um contrato entre a empresa contratante e a subcontratada, podendo ser, inclusive, várias as empresas subcontratadas. A subcontratação se constitui numa forma completamente diferente das que estamos tratando e não há dados a respeito. $\mathrm{Na}$ subcontratação, embora se preserve a autonomia do capital da empresa subcontratada, do ponto de vista do processo de valorização, ela não é autônoma, ela é só aparentemente independente. Isso porque a empresa subcontratada é orientada pela empresa contratante. Por assim dizer, embora cada empresa subcontratada seja autônoma do ponto de vista jurídico, na prática, cada uma delas está sujeita às determinaçóes da contratante. Não há liberdade alguma de fazer a gestão autônoma do empreendimento ou de determinar a tarefa que se tem a cumprir. A empresa subcontratada cumpre os desígnios da outra. Por isso, a subcontratação, tanto quanto a Sociedade de Propósito Específico, muito embora preserve a autonomia do capital envolvido, de fato não são autônomas e se constituem formas de centralização do capital.

A atenção à subcontratação é muito importante quando se analisa o Imobiliário (Real State), uma vez que a prática da subcontratação é bastante comum nas empresas incorporadoras. Estas subcontratam várias empresas, como as de pesquisa de mercado, como as de escritórios de arquitetura, as de consultorias jurídicas e as empresas de propaganda e marketing. No caso da Construção, isso se repete, uma vez que é próprio dela a subcontratação de mão de obra, de equipes de serviços e obras para a realizaçáo de trabalho e de tarefas parcelares do construir.

\section{As maiores empresas incorporadoras, construtoras e vendedoras. A abertura de açóes na bolsa de valores como um dos elementos da reestruturaçáo imobiliária. Um olhar a partir de Sáo Paulo.}

As maiores dentre as maiores

Quais as grandes empresas do imobiliário, da construção e, também, quais as grandes empresas vendedoras de imóveis que atuam na Região Metropolitana de São Paulo? Teriam elas se utilizado da estratégia de abertura de seu capital na bolsa de valores como um dos mecanismos de concentrar e centralizar capitais a indicar um aspecto importante da reestruturação imobiliária?

Apresentamos a seguir o Quadro 2, Quadro 3, Quadro 4 e o Quadro 5 que classificam as maiores empresas incorporadas, construtoras e vendedoras, em 2010. Todas elas registram os lançamentos residenciais, quer verticais ou horizontais, bem como todos os lançamentos de prédios de escritórios. 
QUAdro 2 | Regiáo Metropolitana de Sáo Paulo. Incorporadoras - Total de empresas: 710 (2010)

\begin{tabular}{|c|c|c|c|c|c|c|c|}
\hline \multirow{2}{*}{ EMPRESAS } & \multirow{2}{*}{$\%$} & \multicolumn{2}{|c|}{$\mathrm{N}^{\circ}$ DE UNIDADES } & \multicolumn{2}{|c|}{$\begin{array}{c}\text { ÁREA TOTAL } \\
\text { EM M }\end{array}$} & \multicolumn{2}{|c|}{ PRODUTO TOTAL (R\$) } \\
\hline & & $\mathbf{N}^{\mathbf{0}}$ ABS. & $\%$ & $\mathbf{N}^{\mathbf{0}}$ ABS. & $\%$ & $\mathbf{N}^{\mathbf{0}}$ ABS. & $\%$ \\
\hline 1a Cyrela Brazil Reality & 5,3 & 5.121 & 6,4 & $604.097,20$ & 5,9 & $1.534 .479 .669,94$ & 6,1 \\
\hline 2a Gafisa & 5,1 & 4.019 & 5,1 & $596.280,80$ & 5,8 & $1.500 .825 .705,50$ & 6 \\
\hline 3a Even & 4,5 & 3.779 & 4,8 & $554.558,50$ & 5,4 & $1.479 .777 .415,87$ & 5,9 \\
\hline As 10 primeiras empresas & 31,7 & 28.201 & 35,5 & $3.817 .240,80$ & 37,2 & $9.874 .774 .223,89$ & 39,2 \\
\hline
\end{tabular}

FONTE ELABORAÇÃo PRÓPRIA. EMBRAESP. EMPRESA BRASILEIRA DE ESTUdOS DE PATRIMÔNIO. DISPONÍVEL EM HTTP://WWW.EMBRAESP.COM.BR

QUAdro 3 | Região Metropolitana de São Paulo. Construtoras - Total de empresas: 574 (2010)

\begin{tabular}{|c|c|c|c|c|c|c|c|}
\hline \multirow{2}{*}{ EMPRESAS } & \multirow{2}{*}{$\begin{array}{c}\text { \% DO } \\
\text { MERCADO }\end{array}$} & \multicolumn{2}{|c|}{$\begin{array}{c}\mathrm{N}^{\mathbf{O}} \text { DE } \\
\text { UNIDADES }\end{array}$} & \multicolumn{2}{|c|}{  } & \multicolumn{2}{|c|}{$\begin{array}{c}\text { PRODUTO TOTAL } \\
\text { LANÇADO (R\$) }\end{array}$} \\
\hline & & $\mathbf{N}^{\mathbf{0}}$ ABS. & $\%$ & $\mathbf{N}^{\mathbf{O}}$ ABS. & $\%$ & No ABS. & $\%$ \\
\hline 1a Gafisa & 4,7 & 3.897 & 4,9 & $524.273,52$ & 5,1 & $1.518 .058 .500,00$ & 6 \\
\hline 2a Even & 4 & 3.737 & 4,7 & $482.382,12$ & 4,7 & $1.385 .795 .011,94$ & 5,5 \\
\hline 3a Cyrela Brasil Realty & 3,9 & 2.997 & 3,8 & $477.667,92$ & 4,7 & $1.247 .466 .643,34$ & 5,1 \\
\hline As 10 primeiras empresas & 28,9 & 28.201 & 35,5 & $3.288 .405,09$ & 32,1 & $8.771 .469 .564,80$ & 34,9 \\
\hline
\end{tabular}


DISPONÍVEL EM HTTP://WWW.EMBRAESP.COM.BR

QUAdro 4 | Regiáo Metropolitana de São Paulo. Vendedoras - Total de empresas: 396. Porcentagem do mercado e $n^{\circ}$ de unidades lançadas (2010)

\begin{tabular}{|l|c|c|c|c|c|c|c|}
\hline \multicolumn{1}{|c|}{ EMPRESAS } & $\begin{array}{c}\text { No DE } \\
\text { MERCADO } \\
\text { MNIDADES }\end{array}$ & \multicolumn{2}{|c|}{ ÁREA TOTAL EM M2 } & \multicolumn{2}{c|}{$\begin{array}{c}\text { PRODUTO TOTAL } \\
\text { LANÇADO (R\$) }\end{array}$} \\
\hline 1a Gafisa & 4,7 & 3.897 & 4,9 & $524.273,52$ & 5,1 & $1.518 .058 .500,00$ & 6 \\
\hline 2a Even & 4 & 3.737 & 4,7 & $482.382,12$ & 4,7 & $1.385 .795 .011,94$ & 5,5 \\
\hline 3a Cyrela Brasil Realty & 3,9 & 2.997 & 3,8 & $477.667,92$ & 4,7 & $1.247 .466 .643,34$ & 5,1 \\
\hline As 10 primeiras empresas & 28,9 & 28.201 & 35,5 & $3.288 .405,09$ & 32,1 & $8.771 .469 .564,80$ & 34,9 \\
\hline
\end{tabular}

FONTE ELABORAÇão PRÓPRIA. EMBRAESP. EMPRESA BRASILEIRA DE ESTUdos DE PATRIMÔNIO. DISPONÍVEL EM HTTP://WWW.EMBRAESP.COM.BR 
QUADro 5 | Região Metropolitana de São Paulo. Vendedoras - Total de empresas: 396. Área total construída e produto lançado (2010)

\begin{tabular}{|c|c|c|c|c|}
\hline \multirow{2}{*}{ EMPRESAS } & \multicolumn{2}{|c|}{ ÁREA TOTAL CONSTRUÍDA (EM M²) } & \multicolumn{2}{|c|}{ PRODUTO TOTAL LANÇADO (R\$) } \\
\hline & $\mathbf{N}^{\mathbf{o}}$ ABS. & $\%$ & No ABS. & $\%$ \\
\hline 1a Lopes & $1.674 .688,44$ & 16,3 & $5.270 .697 .138,27$ & 21 \\
\hline 2a Abyara Brokers & $1.238 .638,43$ & 12,1 & $3.554 .059 .445,51$ & 14,1 \\
\hline 3a Fernando Mera & $752.504,55$ & 7,3 & 1.783.656.311,08 & 7,1 \\
\hline As 10 primeiras empresas & $6.658 .366,29$ & 65 & $17.808 .239 .593,51$ & 70,8 \\
\hline
\end{tabular}

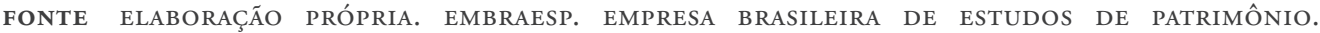
DISPONÍVEL EM HTTP://WWW.EMBRAESP.COM.BR

Analisando os dados a respeito das Incorporadoras, vemos que as 10 primeiras empresas dominam cerca de $31,7 \%$ do mercado e metade dessa porcentagem está nas mãos de apenas 3 empresas: a Cyrela Brazil Realty, a Gafisa e a Even. O número de unidades sobre o controle das 10 primeiras empresas é da ordem de $35,5 \%$, que representa o domínio sobre quase 30.000 unidades, quase $40 \%$ das unidades totais. E, quanto ao produto total, essas 3 empresas detém $40 \%$ do total, quase 10 trilhóes de reais, que equivale mais ou menos a 5 trilhóes e meio de dólares.

Dizendo respeito às Construtoras, a mesma equação em termos de dados se repete, apenas com um pequeno descenso. E são as mesmas empresas que ocupavam as 3 primeiras posiçóes no ranking das incorporadas que aparecem nas mesmas posiçóes quando se trata de construtoras.

Já no caso das Vendedoras, o domínio das grandes empresas é ainda maior. Elas têm em sua carteira cerca de $60 \%$ dos lançamentos e da área total construída e $70 \%$ do produto total lançado, que corresponde a quase 18 trilhóes de reais, mais ou menos o equivalente a 10 trilhóes de dólares. Repetem-se os dois primeiros lugares para a Cyrela Brazil Realty e a Gafisa. Mas, no que diz respeito à porcentagem do mercado que as Vendedoras detêm e a porcentagem do número de unidades lançadas, o terceiro lugar fica com a empresa Habitcasa. Porém, quando se trata da área total construída e do produto total lançado, o terceiro lugar fica com a empresa Fernando Mera, deslocando a Habitcasa para o $4^{\circ}$ lugar. Vale ressaltar que todas essas empresas atuam como Incorporadoras, Construtoras e Vendedoras.

Sendo o mercado imobiliário de Sáo Paulo o maior do país, podemos afirmar, sem sombra de dúvida, que no mercado imobiliário brasileiro predominam as grandes empresas e que a dimensão dessas empresas guarda relação com os processos de concentração e centralização do capital, estratégia utilizada para a centralização do capital, fazendo-as se agigantarem. A título de exemplo de centralização do capital, vejamos o caso da Gafisa, que revela claramente o movimento de alteração na sua constituição jurídica a expressar uma intensa centralização do capital.

A Gafisa, que tem entre suas marcas a Alphaville, originou-se da empresa GAF constituída em 1954. Segundo seu site na internet, em 1997, a empresa GF 
Investimentos S.A e suas afiliadas estabeleceram uma parceria com a GAF e criaram a Gafisa. Em 2004, passou por uma reestruturação societária tendo o controle passado a ser exercido pela GP. No ano seguinte, a Equity International adquiriu $32 \%$ da GP. Em 2006, foi criada a GP Vendas, uma nova subsidiária, reduzindo o número de corretores externos. Em 2007, é criada uma nova subsidiária, a FIT Residencial Empreendimentos Imobiliários Ltda, etc.

\section{A abertura de capitais na bolsa de valores}

Mencionamos a abertura de capitais na bolsa de valores como uma estratégia de ampliação da magnitude do capital de uma empresa. É importante assinalar que essa se constitui numa estratégia empresarial de crescimento e de aumento da capacidade competitiva de uma empresa. Também afirmamos que essa mesma estratégia pode significar uma alavanca que também centraliza capitais. Aparentemente, isso parece ser uma incoerência, pois uma empresa ao abrir capitais na bolsa de valores está pulverizando a propriedade jurídica de seu capital. Ora, na medida em que a abertura de capitais na bolsa de valores significa captaçáo de dinheiro e posteriores emissóes de açóes, isso traz à empresa controladora, a possibilidade de comprar outras empresas, já que essas açóes podem ser convertidas em dinheiro. Isso se traduzirá, no final, em centralização do capital.

A abertura de capitais na bolsa de valores significa, claramente, para uma empresa, a ampliação das possibilidades de financiamento externo, que é diferente daquele procedente de financiamentos obtidos junto a bancos e instituiçôes financeiras. As empresas brasileiras podem se valer, ainda, das "debêntures, notas promissórias, Certificados de Recebíveis Imobiliários - CRI, Fundo de Investimento em Direitos Creditórios - FIDC, Fundos de Investimentos Imobiliários e contam, também, com linhas específicas de financiamento dentro do Sistema Financeiro da Habitação - SFH e Sistema Brasileiro de Poupança e Empréstimo - sBpe e das carteiras hipotecárias das instituiçóes financeiras" (Tavares, 2008, p. 45). Há, portanto, uma ampla gama de financiamento ao setor.

Todo esse arrolado de expedientes acima assinalado, teve apenas o intuito de mostrar que há várias formas do setor imobiliário captar recursos no sistema financeiro. Essas formas não são nenhuma inovação.; esse entrelaçamento sempre existiu. $\mathrm{O}$ que temos na contemporaneidade é a multiplicação de expedientes que reúne os dois; ou seja, o setor imobiliário e o setor financeiro. Melhor dizendo, expedientes que mais que os reúne, os mescla estreitamente, integrando-os.

Se a relação do setor imobiliário com o setor financeiro, em si, não se constitui uma inovação, a abertura de açóes na bolsa de valores pelas empresas Imobiliárias (Real State) é , sim, uma novidade. Novidade que no caso brasileiro se situa a partir de 2005, portanto, uma novidade bastante recente.

Buscando exemplificar o quanto pode ser impactante a abertura de açóes na bolsa de valores, lembremos o caso da Cyrela Brazil Realty, que aparece em primeiro lugar no ranking das empresas incorporadoras do Brasil. Segundo a reportagem de Trevisan (2006), a Cyrela, que atuava no segmento de imóveis residenciais, se fundiu com a Brasil Realty, a qual atuava no segmento de imóveis comerciais. Em 
2006, lançou novas açôes na bolsa de valores e em apenas 10 meses conseguiu elevar em $480 \%$ o valor de mercado de suas ações.

O Quadro 6 lista as empresas incorporadoras de empreendimentos imobiliários, as denominadas Imobiliárias (Real State), que abriram açóes na bolsa de valores entre 2005 a 2007. Os valores lançados aparecem em duas colunas. A primeira coluna diz respeito à oferta primária e, a outra, à oferta secundária. Chama-se de oferta primária o lançamento, por uma empresa, de novas açóes no mercado e denomina-se oferta secundária as açóes negociadas posteriormente. Daí a necessidade da coluna que registra a data de início da negociação. Obrigatoriamente são as instituiçóes integrantes do sistema de valores mobiliários que fazem a intermediação. A última coluna da tabela registra a porcentagem de investidores estrangeiros. Como observou Martins (2010), "os investidores que tenham seus recursos fora do país, ainda que sejam brasileiros, irão aparecer nesta relação como investidores internacionais” (p. 17).

QUADRO 6 | Empresas incorporadoras de empreendimentos imobiliários listadas na Bovespa, volume captado e participaçáo de investidor estrangeiro

\begin{tabular}{|c|c|c|c|c|}
\hline EMPRESA & $\begin{array}{c}\text { DATA DE } \\
\text { INÍCIO DA } \\
\text { NEGOCIAÇÃO }\end{array}$ & $\begin{array}{c}\text { VALOR } \\
\text { LANÇADO } \\
\text { (R\$ MIL) } \\
\text { OFERTA } \\
\text { PRIMÁRIA }\end{array}$ & $\begin{array}{c}\text { VALOR } \\
\text { LANÇADO } \\
\text { (R\$ MIL) } \\
\text { OFERTA } \\
\text { SECUNDÁRIA }\end{array}$ & $\begin{array}{c}\text { PARTICIPAÇÁO } \\
\text { DE INVESTIDOR } \\
\text { ESTRANGEIRO } \\
\left(^{*}\right)\end{array}$ \\
\hline Brascan Residencial Properties S.A. & $20-10-2006$ & 940.000 & 248.000 & 87,4 \\
\hline $\begin{array}{l}\text { Camargo Corrêa Desenvolvimento } \\
\text { Imobiliário }\end{array}$ & 30-01-2007 & 478.500 & 43.500 & 55,6 \\
\hline Company S.A. & 01-03-2006 & 208.000 & 73.600 & 63,6 \\
\hline \multirow{2}{*}{$\begin{array}{l}\text { Cyrela Brazil Ralty S.A. } \\
\text { Empreendimentos e Participaçóes }\end{array}$} & 01-07-2005 & 511.000 & 391.200 & 25,6 \\
\hline & 20-07-1996 & 728.700 & 109.200 & 75,5 \\
\hline Even Construtora e Incor, S.A. & $30-03-2007$ & 460.000 & 0 & 52,5 \\
\hline \multirow{2}{*}{ Gafisa S. A. } & $16-02-2006$ & 494.400 & 432.600 & 72,2 \\
\hline & $19-03-2007$ & 487.812 & 683.493 & 66,9 \\
\hline Klabin Segall S. A. & 06-10-2006 & 375.500 & 181.700 & 65,1 \\
\hline P D G Realty & 25-01-2007 & 420.000 & 228.395 & 93,4 \\
\hline Rodobens Negócios Imobiliários & 30-01-2007 & 390.000 & 0 & 67 \\
\hline Rossi Residencial S.A. & $14-02-2006$ & 612.500 & 250.000 & 80,3 \\
\hline Tecnisa & $31-01-2007$ & 590.652 & 200.651 & 60,8 \\
\hline Total & & 6.697 .064 & 2.842 .339 & \\
\hline
\end{tabular}



FONTE BOVESPA, 2007, APUD: TAVARES (2008, P. 58)

Os dados indicam um grande volume negociado, chegando perto de 10 trilhóes de reais, cerca de 5 trilhóes e meio de dólares. Também apontam para a grande participação de investidores estrangeiros, mesmo considerando-se a ressalva feita por Martins (2010). Metade das empresas que ocupam o topo no ranking das 
incorporadas abriram açóes na bolsa de valores. E, dentre elas, as que ocupam os 3 primeiros lugares: a Cyrela, a Gafisa e a Even.

A pesquisa efetuada por Tavares (2008) sobre a estrutura de financiamento das incorporadoras concluiu que as empresas que emitiram açóes nos anos de 2005, 2006 e 2007 tiveram "reduçáo do endividamento e aumento da liquidez, impulsionada pelos recursos captados, os quais foram prioritariamente destinados ao fortalecimento do banco de terrenos e às aplicaçóes financeiras" (p. 113). Com isso, o Imobiliário (Real State) se tornou menos dependente de financiamento bancário e as instituiçóes financeiras puderam ampliar a oferta de crédito imobiliário ao consumidor final.

Tavares (2008) diz que o aumento da liquidez das empresas fortaleceu o banco de terrenos das empresas. Vale dizer o quanto esse banco de terrenos é estratégico para o Imobiliário (Real State), ou seja, para os produtos e empreendimentos imobiliários. Isso porque o estoque de terrenos sempre foi um elemento de extrema importância para uma empresa imobiliária, já que qualquer aumento no preço dos terrenos significa um risco ao empreendimento imobiliário. Ter um bom estoque de terrenos se constituiu sempre num elemento importante para garantir a competitividade no mercado. Um custo, na verdade um falso custo de produção, que náo se pode esquecer.

Em resumo, a expansão da magnitude dos capitais envolvidos no setor imobiliário, o crescimento do número de fusões, a multiplicação das formas de financiamento das empresas, incluindo-se aí a estratégia de abertura de açóes na bolsa de valores, são elementos (mas, não os únicos) da reestruturação imobiliária.

Uma reestruturação imobiliária na qual há um entrelaçamento íntimo entre o setor imobiliário e o financeiro. Dizer apenas que há uma articulaçâo como entre o setor imobiliário e o financeiro é dizer muito pouco. Preferimos nos referir a uma integração, uma vez que a ideia de articulaçáo mantém cada termo independente, embora relacionados. Já na ideia de integração a independência de cada um deles (imobiliário e financeiro) se dilui um no outro.

O que procuramos mostrar é que no interior do setor imobiliário se gestam movimentos que fazem expandir o capital. Demos destaque ao processo de centralização do capital e às variadas e múltiplas formas e estratégias de financiamento do setor.

\section{Consideraçóes finais}

O imóvel, como dissemos, se constituiu numa mercadoria particular devido ao fato de conter, em si, o terreno, quando não é o próprio terreno que se constitui a mercadoria a ser vendida e comprada. O terreno, sob o crivo da propriedade da terra e como um bem econômico, é indispensável à produção imobiliária e isso faz com que as incorporadoras e construtoras constituam um banco de terrenos. Essas buscam ter um estoque de terrenos para assegurar a continuidade da realizaçáo de seus planos. Isso porque a propriedade da terra é um pressuposto para a produçáo imobiliária e este tende a escapar das máos dos incorporadores e construtores. Controlar esse pressuposto, essa condição irreprodutível, é fundamental, o que se traduz na necessidade de se ter um estoque constantemente renovado. 
A pesquisa de Tavares (2008) deixou claro que com a abertura de açóes na bolsa de valores dois fatos importantes ocorreram: o primeiro, relacionado à maior liquidez das empresas cujos recursos, em grande parte, foram destinados ao fortalecimento do banco de terrenos delas; o segundo, que uma vez que o Imobiliário (Real State) se tornou menos dependente de financiamento bancário, os agentes financeiros buscaram ampliar a oferta de crédito imobiliário ao consumidor final.

A partir de 2004, com a estabilidade da economia num contexto de crescimento econômico, houve uma significativa expansão do crédito no Brasil. Mesmo com contágio da crise de 2008, que desacelerou o crédito proveniente dos bancos privados, o crédito se expandiu porque essa desaceleração se fez acompanhar pela oferta dos bancos públicos, garantindo aí a continuidade e certa expansão do setor imobiliário. Generalizou-se o crédito para a aquisição de imóveis, financiando-se o setor imobiliário e se traduzindo em endividamento para o consumidor final. Constitui-se, assim, de forma intrínseca à lógica imobiliária contemporânea, o endividamento do consumidor final.

Do ponto de vista do consumidor final do imóvel, tudo parece indicar que quando se fecha um negócio se está comprando um imóvel. No entanto, ao se comprar um imóvel por meio de um financiamento, o que se está comprando vai além do imóvel adquirido, seja ele uma casa, um escritório ou um terreno; o que se está comprando, junto com o imóvel, é essencialmente uma dívida.

Aqui reside um dos segredos da produção do espaço urbano na contemporaneidade. Embora a parte visível nessa produção seja os imóveis, o que fica obscurecido é o endividamento, que, de fato, é o principal. É o principal porque o endividamento imobiliário é que se torna o propulsor, o motivador da continuidade da produção imobiliária. O que é necessário é produzir a dívida e os juros composto do dinheiro investido. O que é necessário é vender, aumentando o valor representado pela massa de dinheiro em circulação. Dessa forma entrelaça-se, pelo lado do consumo, o comprador final do imóvel ao setor imobiliário e ao setor financeiro. Nas duas pontas, na produção e no consumo, o imobiliário e o financeiro se mesclam.

Metamorfoseia-se, nessas bases, o urbano, orientado pela centralização do capital do setor imobiliário e pelo crédito ao consumidor. Qualquer atraso do consumidorcomprador-endividado que signifique possibilidade de não saldar o pagamento do imóvel, faz com que sua propriedade lhe seja tomada. Para a produçáo imobiliária, o desafio permanente é diferente do consumidor-comprador endividado. O desafio que se coloca é o de se assenhorar de um estoque de terras que busque manter a continuidade dos planos e investimentos, procurando controlar o que dissemos ser incontrolável, a propriedade da terra, a qual cobra sempre o seu tributo.

Os terrenos no interior da malha urbana mais densa, se tiverem capacidade de abrigar mais densidade e volume de construção e maior número de unidades imobiliárias construídas, são os que podem render bom negócio. São eles os eleitos para a construção de edifícios suntuosos ou do segmento de escritórios primer fazendo multiplicar as centralidades da metrópole, que marcam paisagens urbanas com torres imponentes de edifícios. É aqui que reside um dos segredos da multicentralidade, conformada pelos investimentos imobiliários do segmento de escritórios e do de shopping-centers, em especial. Assim, se criam novas centralidades, menos pelas 
necessidades do desenvolvimento urbano da cidade em desempenhar as funçóes de comércio e de serviços, mas muito mais devido à necessidade dos investimentos atingirem preços mais altos para continuar a reprodução do capital do setor imobiliário.

Os terrenos mais longínquos, nos quais a densidade urbana se apresenta menor, possuem dimensóes maiores. Trata-se, muitas vezes, de terrenos industriais ou rurais que têm preços reduzidos em comparaçáo a outros terrenos localizados no interior da cidade. Esses terrenos quase sempre afastados do frenesi do centro urbano, longe do burburinho e agito da cidade apresentam-se quase sem infraestrutura urbana. São os privilegiados para a construção de unidades horizontais, sejam voltadas para alta renda ou para extratos populares, já que o preço da terra é relativamente menor do que o das áreas mais centrais.

Ao falar do crescimento territorial da cidade dos anos 70 do século xx, Léfebvre (1976) já falava em explosão da cidade. Dizia ele: a "cidade se estende desmesuradamente; ela explode... As extensóes urbanas (subúrbios, periferias próximas ou longínquas) são submetidas à propriedade da terra, às suas consequências: renda fundiária, especulação, rarefação espontânea ou provocada etc.” (p. 178).

Construir cada vez mais longe passa a ter o sentido de se afastar das mazelas da cidade. Aquilo que era feio vira bonito. $\mathrm{O}$ mato, a falta de arruamento, a precária infraestrutura urbana, aparece, agora, valorizada e objeto de desejo. A apologia da natureza se reveste de discursos sobre o bucólico, o ecológico e o sustentável. Ir para longe aparece como possibilidade real de se fugir dos tormentos e barulhos ensurdecedores da cidade. O transitar pelas ruas da cidade e o cruzar com todos os cidadãos é negado. A aspiração é de se apartar dos diferentes. Esse apartar-se é propagandeado pelo marketing ímobiliário com a apologia da segurança e de investimento com valorização imobiliária garantida.

Bolsôes exclusivos e homogêneos de residências se desenvolvem. A metamorfose urbana se traduz em aglomerados de pastilhas de mosaicos que não se justapóem desenhando uma figura. Os agrupamentos de pastilhas estão separados e o que eles compóem é uma grande aglomeraçáo difusa. Esses agrupamentos constituem-se em territórios segregados onde se tem a inclusão de uns e a exclusão de muitos.

O território urbano se apresenta, assim, fragmentado. Na segregação territorial e social que metamorfoseia o urbano, seria possível se restituir a cidade? Nossa resposta é que não é possível. A cidade se perdeu nas tramas do desenvolvimento imobiliário. O negócio imobiliário é a instrumentalização mercantil da privatização do espaço; um negócio de compra e venda de parcelas da cidade. Por mais que se diga sobre tudo isso e se derramem em palavras, tudo se resume ao fato de que a cidade e o urbano são diluídos numa realidade na qual o imobiliário é uma mercadoria particular que compromete o uso da cidade. 


\section{Referencias bibliográficas}

Aglietta, M. (1979). Regulación y crisis del capitalismo. La experiencia de los Estados Unidos. México, España, Argentina, Colombia: Siglo Veintiuno Editores.

Léfebvre, H. (1971). L’idéologie structuraliste. Paris: Éditions Anthropos.

Léfebvre, H. (1976). Tiempos equivocos. Barcelon: Kairós.

Polanyi, K. (1980) A Grande Transformação: as origens de nossa época. Rio de Janeiro: Editora Campus.

Martins, F. E. da S. (2010). A (re)produção social da escala metropolitana: um estudo sobre a abertura de capitais nas incorporadoras e sobre o endividamento imobiliário urbano em São Paulo. Tese de Doutorado em Geografia Humana. Faculdade de Filosofia, Letras e Ciências Humanas. Universidade de São Paulo, São Paulo.

Miranda, J. C. \& Martins, L. (2000). Fusōes e aquisiçôes de empresas no Brasil. Economia e Sociedade, 14: 67-88. Disponível em http://www.uff.br/sta/textos/fv001.pdf

Tavares, R. (2008). A estrutura de financiamento das empresas brasileiras abertas do setor de construção civil incorporadas de empreendimentos imobiliários: um estudo comparativo. Tese de Doutorado em Economia. Faculdade de Economia, Administraçáo e Contabilidade - Universidade de São Paulo, São Paulo.

Trevisan, C. (2006, 3 de Abril). Valor da Cyrela cresce 480\% em dez meses. Folha de São Paulo. Disponível em http://www1.folha.uol.com.br/folha/dinheiro/ult91u106511.shtml. 